\title{
Speaking Pyramid sebagai Media Pembelajaran Kosa Kata Bahasa Inggris Anak Usia 5-6 Tahun
}

\author{
Astien Liyana $^{1 \bowtie}$, Mozes Kurniawan ${ }^{2}$ \\ PG-PAUD, FKIP, Universitas Kristen Satya Wacana Salatiga
}

\begin{abstract}
Abstrak
The aim of this study is to develop speaking pyramid as an English vocabulary learning media for children 5 to 6 years old in TK Kanisius Jimbaran. This is a research and development. We developed speaking pyramid through 5 stages: (1) potential problems, (2) data collection, (3) product design, (4) design validation, and (5) design revisions. The subjects in this study are students of TK Kanisius Jimbaran. We collected data through observation, questionnaire and unstructured interview. Then, we analyzed data in descriptive statistics. The result shows that speaking pyramid is "appropriate" with some improvements by the material expert and "very appropriate" by the media expert. Therefore, speaking pyramid can be used an an English vocabulary learning media to the next trial stage. However, revisions are required.
\end{abstract}

Keywords: speaking pyramid, English vocabulary, research and development, medium of learning

\begin{abstract}
Abstrak
Penelitian ini bertujuan untuk mengembangkan media speaking pyramid sebagai media pembelajaran kosa kata bahasa Inggris pada anak usia dini 5-6 tahun di TK Kanisius Jimbaran. Penelitian ini termasuk jenis Research and Development. Produk yang dikembangkan dalam penelitian ini adalah media speaking pyramid yang berisi materi media pembelajaran kosa kata bahasa Inggris bagi anak. Subjek penelitian dalam penelitian ini adalah siswa TK Kanisius Jimbaran. Teknik pengumpulan data dilakukan dengan observasi, wawancara tidak terstruktur dan angket. Data dianalisis secara deskriptif kuantitatif dan kualitatif. Hasil penelitian menunjukkan bahwa, pada uji validitas media speaking pyramid sebagai media pembelajaran kosa kata bahasa Inggris pada anak usia 5-6 tahun termasuk dalam kategori "sesuai" dengan sedikit perbaikan yang dilakukan dalam tahap revisi dan uji validitas media untuk materi termasuk dalam kategori "sangat sesuai" dengan sedikit perbaikan yang dilakukan dalam tahap revisi. Dengan demikian, media speaking pyramid sebagai media pembelajaran kosakata bahasa Inggris dapat digunakan untuk tahap selanjudnya yaitu tahap uji coba produk.
\end{abstract}

Kata Kunci: speaking pyramid, kosakata bahasa Inggris, research and development, media pembelajaran

@ Jurnal Obsesi Prodi PG-PAUD FIP UPTT 2019

$\triangle$ Corresponding author :

Address : Salatiga Jawa Tengah

Email :272015002@student.uksw.edu

ISSN 2356-1327 (Media Cetak)

ISSN 2549-8959 (Media Online) 


\section{PENDAHULUAN}

Bahasa Inggris merupakan bahasa internasional yang telah mendominasi komunikasi ke seluruh dunia. Kesadaran akan pentingnya penguasaan bahasa Inggris di era informasi ini memunculkan upayaupaya untuk mempelajari dan menguasai bahasa tersebut sedini mungkin. (Khairani, 2016)

Bahasa Inggris merupakan bahasa asing di Indonesia Pembelajaran bahasa Inggris harus diberikan kepada anak usia dini karena bahasa Inggris untuk di zaman sekarang sangatlah penting (Widiarina, 2016). Dalam proses pembelajaran sangat diperlukan dengan strategi dan pendekatan yang tepat dan efektif. Keberhasilan pembelajaran bahasa Inggris pada anak usia dini sangat dipengaruhi oleh kemampuan guru dalam menyajikan proses kegiatan belajar mengajar yang menarik dan menyenangkan bagi anak. (Sopya, 2018). Pembelajaran bahasa Inggris akan lebih menyenangkan jika menggunakan media permainan dari pada hanya dengan metode ceramah, karena pada dasarnya anak-anak usia dini lebih menyukai permainan (Krisnawan, 2015)

Berdasarkan hasil wawancara yang penulis lakukan di TK Kanisius Jimbaran, bahwa pelaksanaan yang dilakukan khususnya pembelajaran bahasa Inggris di kelompok usia $5-6$ tahun, belum pernah menerapkan kegiatan yang berkaitan dengan bahasa Inggris baik dalam komunikasi antara guru dan anak ataupun dalam kegiatan pembelajaran. Pada era sekarang ini, bahasa Inggris adalah salah satu bahasa yang sangat dominan dan sangat erat dengan anak usia dini, misalnya games yang menggunakan bahasa Inggris.

Oleh karena itu, pengetahuan bahasa Inggris sangat penting bagi anak untuk siap menghadapi era saat ini. Berdasarkan permasalahan yang telah dikemukakan di atas, maka tujuan penelitian ini untuk mengembangkan media speaking pyramid sebagai alat untuk meningkatkan kosa kata Bahasa inggris pada anak usia 5-6 tahun di TK Kanisius Jimbaran.

Terdapat dua area utama yang menjadi dasar pembagian area perkembangan bahasa anak. Perkembangan bahasa dapat ditinjau dari area perkembangan kemampuan tulis (print) dan area perkembangan kemampuan lisan (oral).

Dalam bahasa memiliki keterampilan yang harus diperhatikan yaitu; menyimak, berbicara, membaca, dan menulis (Khotijah, 2016). Berbicara dapat diperoleh anak dengan (1) meniru, mengamati model baik dari teman sebaya maupun dari orang yang lebih tua dan (2) pelatihan dengan bimbingan dari orang dewasa (Karlina, 2018)

Hal yang perlu dipersiapkan dalam belajar berbicara yaitu: (1) persiapan fisik dan kesiapan mental untuk berbicara, (2) model yang baik untuk ditiru, (3) kesempatan untuk berpraktik, (4) motivasi dan (5) bimbingan. Secara umum, perkembangan berbicara adalah suatu perkembangan terus menerus dan kualitasnya semakin lama semakin baik yang dibagi dalam beberapa periode, yaitu: periode pralingual (preverbal), periode lingual dini (awal verbal), periode diferensiasi, periode pematangan (Karlina, 2018)

Penelitian-penelitian terdahulu melakukan pengembangan beberapa media untuk pembelajaran anak usia dini. Pengembangan Model Media Audio Pembelajaran Bermuatan Permainan Tradisional Untuk Pendidikan Anak Usia Dini (Suparti \& Susanti, 2018). Pengembangan Alat Peraga Pengenalan Tata Surya Bima Sakti Menggunakan Augmented Reality di PAUD (Arifitama, 2017). Pengembangan permainan roda 
putar untuk meningkatkan kemampuan berhitung angka anak usia 5-6 tahun (Novianti, 2015).Anak dimungkinkan untuk merasakan nuansa pembelajaran dan pengalaman baru yang lebih menyenangkan yang kemudian berdampak positif pada peningkatan penguasaan kosakata (Widya, Yuliana, \& Sofiani, 2019)

Media adalah segala sesuatu yang dapat digunakan untuk menyalurkan pesan dari pengirim ke penerima sehingga merangsang pikiran, perasaan, perhatian dan minat serta perhatian siswa sedemikian rupa sehingga proses belajar terjadi (Sadiman, 2014).

Pemanfaatan media pembelajaran yang digunakan dalam penguasaan kosakata bahasa Inggris menunjukkan perannya yang besar. Media pembelajaran adalah alat yang digunakan untuk membantu didalam kegiatan belajar dan mengajar, media tersebut dapat membantu memberikan pengalaman konkret, memotivasi dan membangkitkan minat belajar (Falahudin, 2014). Media bagi anak usia dini dapat berupa: (1) media visual, media yang dapat dilihat; (2) media audio, media yang mengandung pesan dalam bentuk auditif (hanya dapat didengar) yang dapat merangsang pikiran, perasaan, perhatian, dan keamanan anak untuk mempelajari isi tema; dan (3) media audio-visual, merupakan kombinasi dari media audio dan media visual (Zaman, Pd, Eliyawati, Pd, \& Eliyawati, 2010)

Fungsi utama media pembelajaran yaitu sebagai alat bantu mengajar yang ditata dan diciptakan oleh guru untuk mempengaruhi iklim, kondisi, dan lingkungan belajar(Nugrahani, 2011). Empat fungsi lain media pembelajaran, khususnya media visual, yaitu: (1) fungsi atensi, untuk mengarahkan perhatian siswa pada isi materi yang berkaitan dengan makna visual; (2) fungsi afektif, menggugah emosi dan sikap siswa sehingga siswa menikmati pembelajaran; (3) fungsi kognitif, memperlancar pencapaian tujuan pembelajaran dalam hal memahami dan mengingat informasi atau pesan yang terkandung dalam gambar; dan (4) fungsi kompensatoris, mengakomodasi siswa yang lemah dan lambat menerima isi materi yang disajikan dengan teks atau secara verbal (Azhar, 2011)

Terlepas dari berhasil atau tidaknya suatu media pembelajaran Evaluasi dapat dilakukan dengan berbagai cara, seperti diskusi kelas (kelompok atau perorangan), observasi perilaku, evaluasi media yang digunakan. Kriteria mereview perangkat lunak media yang berdasarkan pada: (1) kualitas isi dan tujuan; (2) kualitas instruksional; dan (3) kualitas teknis (Azhar, 2011)

\section{METODE PENELITIAN}

Jenis penelitian yang digunakan adalah research and development. Adapun langkah-langkah yang ditempuh yaitu: (1) potensi dan masalah, (2) pengumpulan data, (3) desain produk, (4) validasi desain, dan (5) revisi desain. Subjek dalam penelitian ini adalah siswa TK Kanisius Jimbaran usia 5-6 tahun. Adapun variabel yang digunakan dalam penelitian ini yakni: media speaking pyramid sebagai variable bebas dan kosa kata bahasa Inggris anak usia 5-6 tahun sebagai variable terikat.

\section{HASIL DAN PEMBAHASAN}

Hasil observasi dan wawancara yang diperoleh menunjukkan bahwa belum pernah diterapkan kegiatan yang berkaitan dengan bahasa Inggris baik dalam komunikasi antara guru dan anak ataupun dalam kegiatan pembelajaran bahasa Inggris untuk kelompok usia 5-6 tahun di TK Kanisius Jimbaran. Namun, guru sudah pernah mengenalkan bahasa Inggris meski 
tidak diterapkan dalam pembelajaran sehari-hari di sekolah tersebut. Hal ini disebabkan karena terbatasnya sumber daya manusia (guru bahasa Inggris) dan guru bahasa Inggris hanya mengajar khusus untuk sekolah SD (sekolah dasar) dan di sekolah TK (taman kanak-kanak) sendiri hanya menjadi guru kelas saja.

Peneliti kemudian merancang peta kompetensi media speaking pyramid berdasarkan Indikator Pencapaian Perkembangan Anak Usia Lahir sampai 6 Tahun oleh Permendikbud No. 146 tahun 2014 (lihat Tabel 1). Peta kompetensi yang telah dibuat kemudian dikembangkan menjadi rancangan peta materi (lihat Tabel 2). Setelahnya peneliti membuat gambaran rancangan isi media secara garis besar (lihat Tabel 3).

Speaking pyramid didesain agar anak tertarik dan tertantang di dalam permainan pada saat proses pembelajaran. Media ini memiliki tiga poin penting yaitu English speaking, involvement, dan assessment dalam permainan. Speaking adalah percakapan yang selalu digunakan dalam kehidupan sehari hari dan pada saat pembelajaran. Involvement memungkinkan keikutsertaan dan keterlibatan siswa dalam proses belajar. Kemudian, guru melakukan assessment berupa penilaian atau evaluasi kepada muridnya saat bermain.

Speaking pyramid memiliki 36 segitiga, masing-masing anak mendapat bagian 11 segitiga diposisinya, kemudian di setiap segitiga tersebut terdapat kartu tersembunyi yang berisikan kosa kata bahasa Inggris. Didalam speaking pyramid tersebut ditengah terdapat tantangan atau kartu yang berisikan perintah dari guru atau hukuman untuk anak yang bermain tersebut. Penilaiannya adalah menggunakan tiga kartu warna berbeda yaitu merah, kuning, dan hijau. Kartu merah memiliki keterangan kurang baik, kartu warna kuning memiliki keterangan baik, dan kartu warna hijau memiliki keterangan sangat baik.

Tabel 1

Peta kompetensi pemahaman bahasa usia 56 Tahun

\begin{tabular}{|l|l|}
\hline Kompetensi Dasar & \multicolumn{1}{|c|}{ Indikator 5-6 Tahun } \\
\hline $\begin{array}{l}\text { Memahami bahasa } \\
\text { reseptif } \\
\text { (menyimak dan } \\
\text { membaca) }\end{array}$ & $\begin{array}{l}\text { Menceritakan kembali apa } \\
\text { yang didengar dengan } \\
\text { kosakata yang lebih }\end{array}$ \\
\hline $\begin{array}{l}\text { Menunjukkan } \\
\text { kemampuan } \\
\text { berbahasa reseptif } \\
\text { (menyimak dan } \\
\text { membaca) }\end{array}$ & $\begin{array}{l}\text { Melaksanakan perintah yang } \\
\text { aturan yang disampaikan } \\
\text { (misal: aturan untuk } \\
\text { melakukan kegiatan memasak }\end{array}$ \\
\hline $\begin{array}{l}\text { Memahami bahasa } \\
\text { ekspresif } \\
\text { (mengungkapkan } \\
\text { bahasa secara } \\
\text { verbal dan non } \\
\text { verbal) }\end{array}$ & $\begin{array}{l}\text { Pendapat dengan kalimat } \\
\text { sederhana dalam } \\
\text { berkomunikasi dengan anak } \\
\text { atau orang dewasa }\end{array}$ \\
\hline $\begin{array}{l}\text { Menunjukkan } \\
\text { kemampuan } \\
\text { berbahasa } \\
\text { ekspresif } \\
\text { (mengungkapkan } \\
\text { bahasa secara } \\
\text { verbal dan non } \\
\text { verbal) }\end{array}$ & $\begin{array}{l}\text { Menunjukkan perilaku senang } \\
\text { membaca buku terhadap buku- } \\
\text { buku yang dikenali }\end{array}$ \\
\hline
\end{tabular}

Tabel 2

Peta Materi

\begin{tabular}{|c|c|c|}
\hline Materi Pokok & Isi Materi & $\begin{array}{c}\text { Penjabaran } \\
\text { Materi }\end{array}$ \\
\hline $\begin{array}{l}\text { Memahami } \\
\text { bahasa reseptif } \\
\text { (menyimak dan } \\
\text { membaca) }\end{array}$ & $\begin{array}{l}\text { Mengenal } \\
\text { Menirukan } \\
\text { Menyebutkan }\end{array}$ & $\begin{array}{l}\text { Jenis-jenis } \\
\text { gambar dan } \\
\text { kosa kata } \\
\text { bahasa Inggris } \\
\text { yang } \\
\text { diterapkan } \\
\text { secara } \\
\text { sederhana } \\
\text { seperti nama } \\
\text { buah, sayur } \\
\text { dan } \\
\text { sebagainya. }\end{array}$ \\
\hline $\begin{array}{l}\text { Menunjukkan } \\
\text { kemampuan } \\
\text { berbahasa } \\
\text { reseptif } \\
\text { (menyimak dan } \\
\text { membaca) }\end{array}$ & $\begin{array}{l}\text { Mengenal } \\
\text { Menirukan } \\
\text { Menyebutkan }\end{array}$ & $\begin{array}{l}\text { Jenis-jenis } \\
\text { gambar dan } \\
\text { kosa kata } \\
\text { bahasa Inggris } \\
\text { yang dapat } \\
\text { dilakukan yaitu } \\
\text { menyebutkan } \\
\text { atau menebak }\end{array}$ \\
\hline
\end{tabular}




\begin{tabular}{|c|c|c|}
\hline & & $\begin{array}{l}\text { kosa kata } \\
\text { bahasa Inggris } \\
\text { seperti nama } \\
\text { buah, sayur, } \\
\text { dan } \\
\text { sebagainya. }\end{array}$ \\
\hline $\begin{array}{l}\text { Memahami } \\
\text { bahasa } \\
\text { ekspresif } \\
\text { (mengungkapka } \\
\text { n bahasa secara } \\
\text { verbal dan non } \\
\text { verbal) }\end{array}$ & $\begin{array}{l}\text { Mengungkapka } \\
\mathrm{n}\end{array}$ & $\begin{array}{l}\text { Anak dapat } \\
\text { mengungkapka } \\
\mathrm{n} \text { apa yang } \\
\text { disampaikan } \\
\text { oleh guru }\end{array}$ \\
\hline $\begin{array}{l}\text { Menunjukkan } \\
\text { kemampuan } \\
\text { berbahasa } \\
\text { ekspresif } \\
\text { (mengungkapka } \\
\text { n bahasa secara } \\
\text { verbal dan non } \\
\text { verbal) }\end{array}$ & $\begin{array}{l}\text { Mengungkapka } \\
\mathrm{n}\end{array}$ & $\begin{array}{l}\text { Anak dapat } \\
\text { menebak atau } \\
\text { mengungkapka } \\
\mathrm{n} \text { apa yang ada } \\
\text { dibalik kartu } \\
\text { kosa kata } \\
\text { bahasa Inggris }\end{array}$ \\
\hline
\end{tabular}

Tabel 3

Garis Besar Isi Media Speaking Pyramid

\begin{tabular}{|c|c|}
\hline Judul & Speaking Pyramid \\
\hline $\begin{array}{l}\text { Materi } \\
\text { pokok }\end{array}$ & $\begin{array}{l}\text { Meningkatkan kosa kata bahasa } \\
\text { Inggris }\end{array}$ \\
\hline $\begin{array}{l}\text { Indikator } \\
\text { Turunan }\end{array}$ & $\begin{array}{l}\text { 1. Mampu mengenal kosa kata } \\
\text { bahasa Inggris secara sederhana } \\
\text { 2. Mampu mengingat kosa kata } \\
\text { bahasa Inggris } \\
\text { 3. Mampu menyebutkan kosa kata } \\
\text { bahasa Inggris } \\
\text { 4. Mampu memperagakan kosa } \\
\text { kata bahasa Inggris }\end{array}$ \\
\hline $\begin{array}{l}\text { Format } \\
\text { Media }\end{array}$ & $\begin{array}{l}\text { 1. Judul media "Speaking } \\
\text { Pyramid" } \\
\text { 2. Kartu kosa kata bahasa Inggris } \\
\text { 3. Kartu point } \\
\text { 4. Bidak permainan } \\
\text { 5. Segitiga warna hitam untuk } \\
\text { tantangan } \\
\text { 6. Kotak peti harta karun } \\
\text { 7. Kunci peti harta karun }\end{array}$ \\
\hline $\begin{array}{l}\text { Cara } \\
\text { Kerja } \\
\text { Media }\end{array}$ & $\begin{array}{l}\text { 1. Setelah membuka permainan } \\
\text { anak diberikan bidak masing- } \\
\text { masing satu dan duduk sesuai } \\
\text { posisi bermain } \\
\text { 2. Kartu kosa kata bahasa Inggris } \\
\text { dibalik dan setelah anak } \\
\text { membuka kartu, anak akan } \\
\text { menebak kosa kata bahasa } \\
\text { Inggris tersebut } \\
\text { 3. Apabila anak dapat menjawab } \\
\text { maka anak akan mendapatkan }\end{array}$ \\
\hline
\end{tabular}

\begin{tabular}{|c|c|}
\hline & $\begin{array}{l}\text { kartu warna hijau, jika anak } \\
\text { dapat menjawab dengan } \\
\text { bantuan guru maka anak } \\
\text { mendapat kartu warna kuning, } \\
\text { jika anak tidak dapat menjawab } \\
\text { maka anak akan mendapatkan } \\
\text { kartu warna merah } \\
\text { 4. Pada saat anak sampai di } \\
\text { segitiga warna hitam anak } \\
\text { tersebut akan mendapat } \\
\text { tantangan untuk mendapatkan } \\
\text { sebuah kunci menuju finish } \\
\text { 5. Sesampainya di finish anak } \\
\text { akan membuka kotak peti harta } \\
\text { karun dan di dalam kotak peti } \\
\text { harta karun tersebut terdapat } \\
\text { sebuah hadiah }\end{array}$ \\
\hline $\begin{array}{l}\text { Gambar } \\
\text { Desain } \\
\text { Media }\end{array}$ & \\
\hline
\end{tabular}

Media speaking pyramid yang dikembangkan kemudian divalidasi terlebih dahulu. Validasi media dilaksanakan oleh ahli media yang mempunyai latar belakang berpengalaman sesuai dengan media yang dikembangkan. Tujuannya untuk mendapatkan informasi, kritik, dan saran agar media speaking pyramid yang dikembangkan menjadi produk yang berkualitas secara aspek isi dan tujuan, teknis, dan instruksional.

Secara umum, speaking pyramid dinilai cukup menarik dan menantang bagi anak untuk memperkaya kosakata bahasa Inggris mereka. Hal ini dikarenakan adanya reward yang diterima apabila anak mampu menyelesaikan permainan terlebih dahulu. Hasil validasi ahli materi menunjukkan hasil jumlah skor sebesar 166 dengan persentase $83 \%$, dan rerata skor sebesar 4,15 dengan rentang rerata skor $X>4,08$ yaitu kategori "sangat sesuai" (lihat Tabel 
4). Berdasarkan hasil tersebut dapat diketahui bahwa media speaking pyramid yang dikembangkan digunakan dengan revisi.

Bahan media berupa kartu dinilai mudah sobek sehingga perlu menemukan bahan lain yang lebih tahan sobek. Bagianbagian yang berpotensi terlepas dan tidak kokoh memungkinkan dapat tertelan anak (Badan Standar Nasional, 2012). Nampak kecenderungan peningkatan kosakata bahasa Inggris lebih dominan dibandingkan meningkatkan kemampuan speaking secara utuh. Assesment yang dilakukan guru sangat terbatas pada observasi.

Tabel 4

Hasil Validasi Ahli Media dan Ahli Materi pada Tiap Aspek

\begin{tabular}{|l|l|l|}
\hline \multirow{2}{*}{\multicolumn{1}{|c|}{ Aspek }} & \multicolumn{2}{c|}{ Skor } \\
\cline { 2 - 3 } $\begin{array}{l}\text { Kualitas Isi dan } \\
\text { Tujuan }\end{array}$ & Ahli Media & Ahli Materi \\
\hline Kualitas Teknis & 67 & 59 \\
\hline Kualitas Instruksional & 23 & 79 \\
\hline Jumlah & 144 & 28 \\
\hline Rentang Rerata Skor & $3,36<X \leq$ & 166 \\
\hline Rerata Skor & 4,08 & $X \leq 4,08$ \\
\hline Kategori Skor & 3,6 & 4,15 \\
\hline & Sesuai & $\begin{array}{l}\text { Sangat } \\
\text { Sesuai }\end{array}$ \\
\hline
\end{tabular}

Setelah valiasi media dilakukan, media Speaking Pyramid yang dikembangkan diuji validitasnya juga oleh ahli materi. Validasi materi dilaksanakan oleh Dosen Fakultas Teknologi dan Informasi (Public Relations, Bahasa Inggris) yang mempunyai latar belakang sesuai dengan materi yang dikembangkan. Tujuan untuk mendapatkan informasi, kritik, dan saran agar materi media speaking pyramid yang dikembangkan memiliki kualitas yang memadai dari aspek isi, tujuan, teknis, dan instruksional.

Bentuk desain speaking pyramid dinilai unik, mekanik menebaknya cukup baik, dan cukup menjawab tujuan pembelajaran kosakata. Hasil validasi ahli media menunjukkan hasil jumlah skor sebesar 144 dengan persentase $72 \%$ dan rerata skor sebesar 3,6 dengan rentang rerata skor $3,36<X \leq 4,08$ kategori "sesuai" (lihat Tabel 4). Berdasarkan hasil tersebut dapat diketahui bahwa media speaking pyramid yang dikembangkan digunakan dengan revisi.

Speaking pyramid digunakan secara manual. Hal ini dimaksudkan agar pesan dan informasi yang disampaikan menjadi lebih jelas, menarik, konkrit dan tidak hanya terbatas dalam kata-kata tertulis atau lisan (Zaman et al., 2010). Beberapa komponen-komponen penyusun media yang tidak perlu dihilangkan agar media secara utuh efisien digunakan. Pembenahan ukuran dan model komponen-komponen penyusun media pun dilakukan. Hal ini berkaitan dengan ukuran media terlalu besar yang dirasa tidak efisien penggunaannya bagi anak. besar kecilnya ukuran sebuah mainan akan berpengaruh terhadap keamanan anak (Badan Standar Nasional, 2012).

Penerapan warna pada kartu dinilai kurang consisten yang dirasa akan membingungkan anak. Diharapkan penerapan warna kartu memungkinkan anak memaknai dengan mudah dan membantu mengarahkan perhatiannya pada isi materi yang berkaitan dengan makna visual (Azhar, 2011)Selain itu, alur permainan dinilai cukup rumit sehingga perlu disederhanakan. Di sisi lain, adanya perombakan pada mekanik dengan memasukkan unsur randomisasi dan unsur kejutan agar permainan dapat berjalan dengan seru demi menimbulkan kegairahan dan motivasi belajar anak (Zaman et al., 2010) 


\section{KESIMPULAN}

Pengetahuan bahasa Inggris sangat penting bagi anak untuk siap menghadapi era saat ini karna bahasa Inggris sudah menjadi bahasa internasional. Oleh karena itu tujuan dari penelitian yang peneliti lakukan apakah kosakata bahasa Inggris anak dapat meningkat dengan menggunakan media speaking pyramid.

Media speaking pyramid yang dikembangkan sesuai untuk diterapkan dalam uji coba sebagai alat untuk meningkatkan kosakata bahasa Inggris pada anak usia 5-6 tahun di TK Kanisius Jimbaran berdasarkan hasil uji validitas yang dilakukan ahli materi dan ahli media dengan rerata skor masing-masing $(4,15)$ dan $(3,6)$ yang termasuk dalam kategori "sangat sesuai" dan "sesuai".

Media Speaking Pyramid yang telah dikembangkan dapat diujicobakan kepada subjek penelitian untuk menguji validitas konstruksi dan analisis faktornya. Dengan demikian, kualitas media tidak hanya valid berdasarkan penilaian ahli materi dan media, tetapi juga valid berdasarkan analisis faktor sehingga dapat terus dikembangkan lebih lanjut dan secara kualitas dapat digunakan dalam lingkup yang lebih luas.

\section{DAFTAR PUSTAKA}

Arifitama, B. (2017). Pengembangan Alat Peraga Pengenalan Tata Surya Bima Sakti Menggunakan Augmented Reality di PAUD. Sisfo, 05(04). https://doi.org/10.24089/j.sisfo.2015. 09.006

Azhar, A. (2011). Media Pembelajaran. Media Pembelajaran, (1), 1-13. https://doi.org/media pembelajaran

Falahudin, I. (2014). Pemanfaatan Media dalam Pembelajaran. Edisi, 1(4), 104117.

Karlina, D. N. (2018). Meningkatkan Kemampuan Berbicara Anak Tk B
Usia 5-6 Tahun Melalui Digital Storytelling Di Tk Apple Kids Salatiga Semester I Tahun Ajaran 2017/ 2018. JPUD - Jurnal Pendidikan Usia Dini, 12(1), 1-11. https://doi.org/10.21009//jpud.121.01

Khairani, A. I. (2016). Pendidikan Bahasa Inggris Untuk Anak Usia Dini. Digilib.unimed.ac.id. Retrieved from http://digilib.unimed.ac.id/id/eprint/4 48

Khotijah. (2016). Strategi Pengembangan Bahasa Anak Pada Anak Usia Dini. Elementary, 2, 35-44.

Krisnawan, G. N. A. (2015). Rancang Bangun Aplikasi Game Edukasi Bahasa Inggris Untuk Anak Berbasis Android. Konferensi Nasional Sistem Dan Informatika (KNS\&I), (86), 955960.

Novianti, R. (2015). Pengembangan permainan roda putar untuk meningkatkan kemampuan berhitung angka anak usia 5-6 tahun. Jurnal Educhild, 4(1), 56-63.

Nugrahani, R. (2011). Media Pembelajaran Berbasis Visual Berbentuk Permainan Ular Tangga Untuk Meningkatkan Kualitas Belajar Mengajar Di Sekolah Dasar. Lembaran Ilmu Kependidikan, 36(1), 35-44. Retrieved from https://journal.unnes.ac.id/nju/index.p $\mathrm{hp} / \mathrm{LIK} /$ article/view/524

Sadiman. (2014). Media Pendidikan Pengertian, Pengembangan, Dan Pemanfaatannya. Tadib. Retrieved from

http://jurnal.radenfatah.ac.id/index.ph $\mathrm{p} /$ tadib/article/view/16

Sopya, I. V. (2018). Pembelajaran Bahasa Inggris Melalui Lagu Pada Anak Usia Dini. ThufuLA: Jurnal Inovasi Pendidikan Guru Raudhatul Athfal, 1(1), 1. https://doi.org/10.21043/thufula.v1i1. 4236

Suparti, Nf., \& Susanti, M. (2018). Pengembangan Model Media Audio Pembelajaran Bermuatan Permainan 
232 | Speaking Pyramid sebagai Media Pembelajaran Kosa Kata Bahasa Inggris

Tradisional Untuk Pendidikan Anak Usia DinI. Jurnal Kwangsan, 5(2), 101.

https://doi.org/10.31800/jtp.kw.v5n2. p101--114

Widiarina, W. (2016). Animasi Interaktif Pengenalan Bagian Rumah Dalam Bahasa Inggris. Seminar Nasional Ilmu Pengetahuan Dan Teknologi Komputer, 421 - INF.425. Retrieved from http://konferensi.nusamandiri.ac.id/pr osiding/index.php/sniptek/article/vie w/381

Widya, W., Yuliana, T. I., \& Sofiani, Y. (2019). Pengajaran Kosakata Bahasa Inggris dengan Media Realia dan Flash Card. Jurnal PkM Pengabdian Kepada Masyarakat, 1(01), 39. https://doi.org/10.30998/jurnalpkm.v1 i01.2359

Zaman, B., Pd, M., Eliyawati, H. C., Pd, M., \& Eliyawati, H. C. (2010). Media Pembelajaran Anak Usia Dini. Media Pembelajaran Anak Usia Dini. Retrieved from http://file.upi.edu/Direktori/FIP/JUR. _PGTK/197010221998022-

Cucu_Eliyawati/Media_Pembelajaran _Anak_Usia_Dini-Ppg_Upi.Pdf 